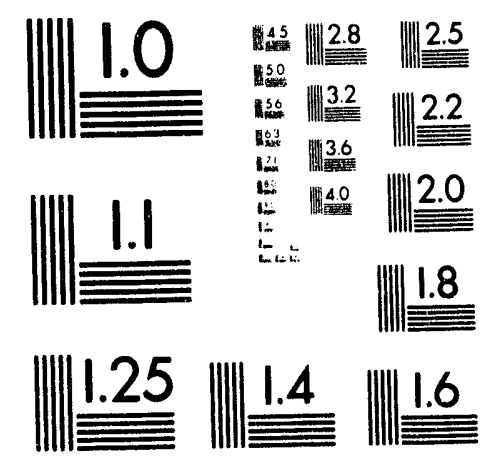



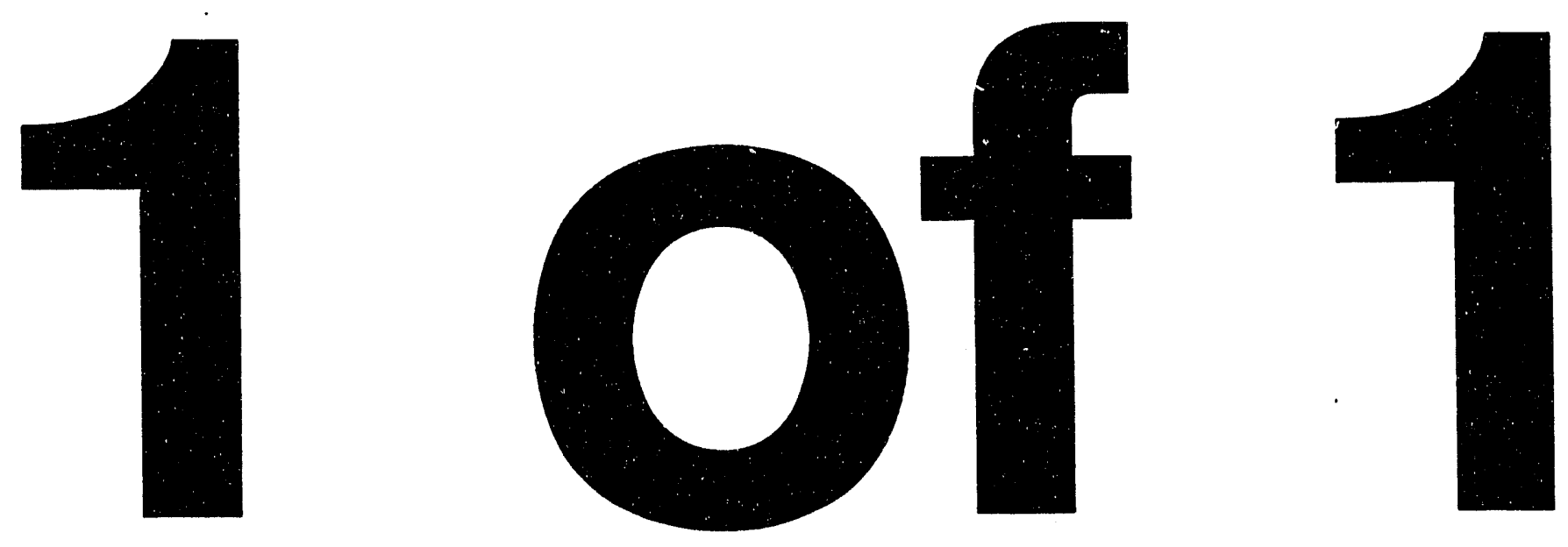
KCP-613-5111

Distribution Category UC-706

\section{CRATERING EVALUATIONS AND RESULTS}

John R. Church

Published August 1993

John R. Church, Project Leader 


\section{Contents}

Section Page

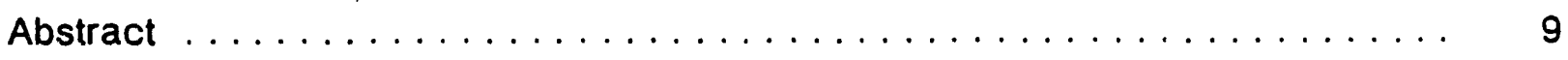

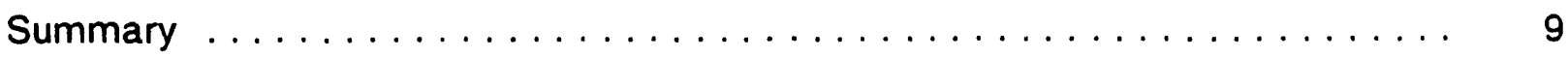

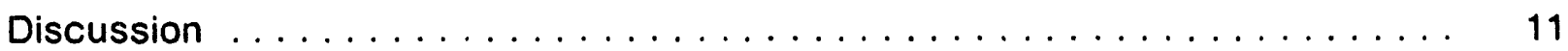

Scope and Purpose $\ldots \ldots \ldots \ldots \ldots \ldots \ldots \ldots \ldots \ldots \ldots \ldots$

Prior Work $\ldots \ldots \ldots \ldots \ldots \ldots \ldots \ldots \ldots \ldots \ldots \ldots \ldots \ldots \ldots \ldots \ldots$

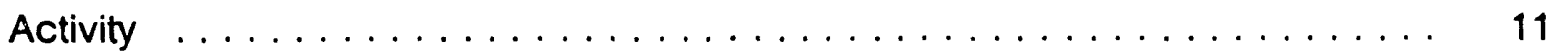

Force-Time-Power Evaluation $\ldots \ldots \ldots \ldots \ldots \ldots \ldots \ldots \ldots$

Aluminum Wire Evaluations $\ldots \ldots \ldots \ldots \ldots \ldots$

Six-Parameter Evaluation $\ldots \ldots \ldots \ldots \ldots \ldots \ldots$

Accomplishments $\ldots \ldots \ldots \ldots \ldots \ldots \ldots \ldots \ldots \ldots \ldots \ldots$

Future Work ............................ 19 


\section{Illustrations}

Figure $\quad$. Page

1 A Transistor With $3 \times 5$-Mil Bond Pads $\ldots \ldots \ldots \ldots \ldots \ldots \ldots \ldots$

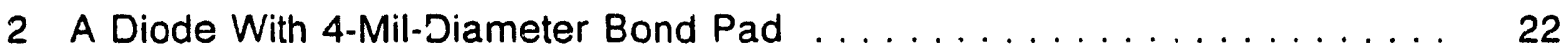

3 Transistor With a 1-Mil Crack on the Perimeter of the Bond Pad . . . . 23

4 Crater Which is $0.5 \mathrm{Mil}$ in the Longest Direction $\ldots \ldots \ldots \ldots \ldots$

5 Considerable Damage to the Silicon in a Crater That is Difficult

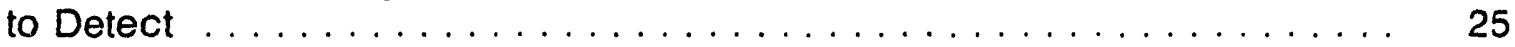

6 Two Different Areas of Damage $\ldots \ldots \ldots \ldots \ldots \ldots$

7 Outline of the Bond After the Metalization Has Been Etched Away . . . . . 27

8 Bonding Experiment, Number of Small Craters $\ldots \ldots \ldots \ldots$

9 Bonding Experiment, Number Large Craters $\ldots \ldots \ldots \ldots . \ldots \ldots$

10 Bonding Experiment, Number of Total Craters . . . . . . . . . . . . . . 29 


\section{Tables}

Number $\quad$ Page

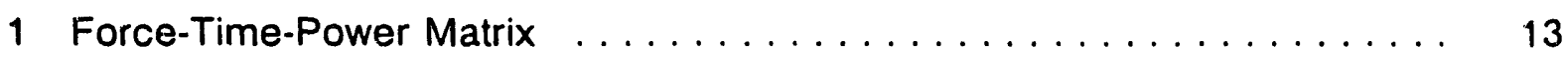

2 Wire Evaluations, Second Vendor $\ldots \ldots \ldots \ldots \ldots \ldots \ldots \ldots$

3 Wire Evaluations, First Vendor $\ldots \ldots \ldots \ldots \ldots \ldots$

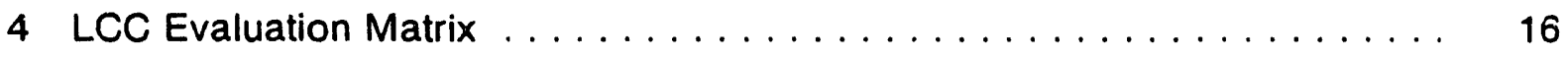

5 LCC Evaluation Matrix Results $\ldots \ldots \ldots \ldots \ldots \ldots \ldots$

6 Old and New Bonding Parameters .................... 19

7 Number of Craters From New Parameters . . . . . . . . . . . . . . . . 19 


\begin{abstract}
Investigations were performed on the 1-mil ultrasonic aluminum wire bonding process to determine how the interaction of the bonding parameters, ultrasonic power, time, force, and aluminum wire, contribute to cratering (cracking or damage to oxide/passivation layers). Investigations revealed that power, time, and force can interact at levels which can contribute to cratering. The age of the aluminum wire can also influence the quality of bonds.
\end{abstract}

\title{
Summary
}

The investigations were performed to reduce and/or eliminate cratering in discrete components.

The bonding evaluations were performed on two Kulicke \& Soffa, Model 1470 , ultrasonic aluminum wire bonders (1 mil) using ICs (integrated circuits) or discrete components which were crater sensitive. Throughout the report all bonding should be assumed to have been performed in the reverse mode unless otherwise noted.
The evaluations revealed that the parameters of power, time, and force can affect the crater rate. A given combination may be found to minimize the quantity of craters, but if the age of the aluminum wire is not considered, tho quantity of craters may increase as the wire ages. 


\section{Discussion}

\section{Scope and Purpose}

The investigation determined the effect of power, time, and force on cratering. The age of the wire was also evaluated to determine the impact it had on the cratering problem. These evaluations were performed to increase quality and reduce the amount of scrap on LCC devices.

\section{Prior Work}

Concern about cratering at AlliedSignal Inc., Kansas City Division (KCD), began during the early packaging efforts of LCC devices (approximately 1988), when bonding to discrete components began. Prior to this time, packaging operations were directed toward IC devices in various package configurations; and failure analysis work did not indicate the presence of crater-related defects.

Electrical testing can give an indication of cratering if there appears to be an increase in leakage current of a device under test, but electrical testing has proven not to be a reliable means of crater detection. To date the only reliable detection method is destructive evaluation by etching the overlying metalization away to reveal the silicon or silicon oxide surface underneath.

Cratering is a phenomenon that occurs intermittently during the ultrasonic aluminum wire bonding process, and it can appear in a variety of sizes. Gross damage can appear as a divot in the silicon, approximately $1 \mathrm{mil}$ in diameter or larger. Minimal damage can appear as a small pit, about one-quarter mil in size or smaller, and can be identified by the small interference fringes originating from the center of the pit. Mechanical damage between these extremes will normally appear as oval or half-moon cracks in the silicon. Smaller mechanical damage has been identified using SEM, but damage this small has not yet been found to penetrate the silicon oxide layer.

Figures 1 through 7 give a visual representation of craters and how they can appear on devices which have been etched back. (All figures in this report appear following the text.)

\section{Activity}

The initial studies on cratering concentrated on the variables of time, force, and ultrasonic energy (power). For an effective evaluation and process characterization all the variables in the process need to be measurable. The need to characterize the bonding process initiated an attempt to measure the ultrasonic energy using an interferometer. Repeated attempts at airning the instrument at the tip of the bond tool failed to obtain readings that were repeatable. The slight vibration in the raised floor, due to the cleair room air handling motors, was sufficient to interfere with the laser beam and the tool tip, which caused intermittent and nonrepeatable readings. Other attempts of mounting the instrument directly to the bonder met with minimal success. 
Because time and force were the only measurable variables, they were basis of the design of the evaluation, and the ultrasonic energy was adjusted until pull strengths and bond deformations were acceptable.

\section{Force-Time-Power Evaluation}

Prior to the first study of the interaction of force, time, and power, a matrix based on these three variables was designed. The settings were tested prior to the evaluation for acceptable bonds, both in appearance and pull strengths. The evaluation used IC dies known to be sensitive to cratering. From the established settings for each variable, a Box-Behnken matrix was designed (Table 1) and a random order run was generated for each setting. Each setting consisted of 120 bonds, 3 devices, 40 bonds per device.

The evaluation was run on one bonder with the same operator, and the complete matrix was bonded without interruption. The wire was 1 -mil aluminum, $1 \%$ silicon. The age of the wire was approximately one year. After completion of wire bonding, the devices were placed in hydrochloric acid for 15 minutes and heated to approximately $150^{\circ} \mathrm{C}$ to etch the aluminum back to expose the silicon oxide. The devices were then inspected (at 200X), and the craters were counted and categorized as small or large and totaled for each bond setting.

Regression analysis was performed on the data generating the following relationships from data accumulated in the bonding evaluation.

$$
\begin{aligned}
& S C=\# \text { of small craters } \\
& L C=\# \text { of large craters } \\
& T C=\# \text { of total craters } \\
& F=\text { force } \\
& P=\text { power } \\
& T=\text { time } \\
& S C=7.43-1.625 \mathrm{~F}-1.550 \mathrm{~T}^{2} \\
& \mathrm{LC}=5.62-2.83 \mathrm{~F} 2-1.08 \mathrm{~T}^{2}-1.5 \mathrm{P} \times \mathrm{T} \\
& T C=12.77-2.125 \mathrm{~F}-2.35 \mathrm{~F}^{2}-2.60 \mathrm{~T}^{2}
\end{aligned}
$$

From the equation for small craters it is interesting to note that the amount of power does not influence the number of small craters. (Figures 8 and 9 represent these relationships graphically.) The fewest number of small craters occur if the force is high $(30 \mathrm{~g})$ and time is low (45 ms). (See Figure 8.) With these settings an expected crater rate would be approximately four small craters every 120 bonds.

The equation for large craters indicates that the number of large craters is influenced by all variables: power, force, and time. If force is set at $30 \mathrm{~g}$, time at $45 \mathrm{~ms}$, and power is at 3.1, a large crater rate of one in 600 bonds can be expected. (See Figure 9.)

The total number of craters is not dependent on the power settings. But again the fewest number of total craters occurs if force is $30 \mathrm{~g}$ and time is $45 \mathrm{~ms}$. These settings will yield approximately six total craters for every 120 bonds. See Figure 10. 
Table 1. Force-Time-Power Matrix

\begin{tabular}{|cccccc|}
\hline $\begin{array}{c}\text { Force } \\
(\mathrm{g})\end{array}$ & Power & $\begin{array}{c}\text { Time } \\
(\mathrm{ms})\end{array}$ & $\begin{array}{c}\text { Small } \\
\text { Craters }\end{array}$ & $\begin{array}{c}\text { Large } \\
\text { Craters }\end{array}$ & Total \\
\hline 30 & 4.3 & 55 & 5 & 2 & 7 \\
30 & 3.1 & 55 & 5 & 4 & 9 \\
20 & 4.3 & 55 & 11 & 2 & 13 \\
20 & 3.1 & 55 & 9 & 3 & 12 \\
30 & 3.7 & 65 & 6 & 1 & 7 \\
30 & 3.7 & 45 & 5 & 0 & 5 \\
20 & 3.7 & 65 & 7 & 2 & 9 \\
20 & 3.7 & 45 & 7 & 4 & 11 \\
25 & 4.3 & 65 & 8 & 3 & 11 \\
25 & 4.3 & 45 & 5 & 6 & 11 \\
25 & 3.1 & 65 & 6 & 6 & 12 \\
25 & 3.1 & 45 & 3 & 3 & 6 \\
25 & 3.7 & 55 & 7 & 6 & 13 \\
25 & 3.7 & 55 & 5 & 5 & 10 \\
25 & 3.7 & 55 & 10 & 6 & 16 \\
\hline
\end{tabular}

Analysis of the data from this evaluation did not indicate that a crater rate of zero could be obtained. The expected number of craters per 120 bonds was unacceptable. Further evaluation was needed to determine if there was an optimum set of parameters that would further reduce cratering.

\section{Aluminum Wire Evaluations}

\section{Vendor Comparisons}

All of production bonding and evaluations performed previously at KCD had been performed with wire from a single vendor. An evaluation was run to compare wire from a different manufacturer to the originally used wire.

Table 2 shows the various combinations evaluated with the second vendor's wire. The individual results were not encouraging, but indications were that the combination which included the time of $30 \mathrm{~ms}$ produced fewer craters. A force setting between 25 and $35 \mathrm{~g}$ with the $30-\mathrm{ms}$ time appeared to be acceptable. The change in the wire vendor did not seem to improve the overall results. 
Table 2. Wire Evaluations, Second Vendor

\begin{tabular}{|cccccccc|}
\hline $\begin{array}{c}\text { Time } \\
(\mathrm{ms})\end{array}$ & $\begin{array}{c}\text { Force } \\
(\mathrm{g})\end{array}$ & Power & $\begin{array}{c}\text { Wire Age } \\
\text { (Months) }\end{array}$ & $\begin{array}{c}\text { Number } \\
\text { of Bonds }\end{array}$ & Craters & Percent & Component \\
\hline 30 & 35 & 2.00 & 18 & 320 & 4 & 1.2 & SA3636 \\
35 & 45 & 2.15 & 18 & 320 & 19 & 5.9 & SA3636 \\
30 & 30 & 2.40 & 18 & 320 & 48 & 15.0 & SA3636 \\
25 & 40 & 2.05 & 18 & 320 & 25 & 7.8 & SA3536 \\
25 & 35 & 1.90 & 18 & 320 & 9 & 2.8 & SA3636 \\
25 & 35 & 2.35 & 18 & 160 & 26 & 16 & SA3636 \\
30 & 25 & 2.10 & 18 & 320 & 5 & 1.6 & SA3636 \\
30 & 35 & 1.90 & 18 & 360 & 6 & 1.7 & SA3636 \\
\hline & & & & 2440 & 142 & 5.8 & \\
\hline
\end{tabular}

\section{Wire Age Evaluations}

It was hypothesized that 1-mil aluminum wire tends to harden with age, but this could not be verified with available equipment at KCD. One vendor was contacted concerning the physical changes of aluminum wire as it ages. Their response was that the wire will get an oxide layer buildup as it ages which makes it more difficult for the bonder to break through the layer for acceptable deformation. Another characteristic of aluminum wire as it ages is the migration of the $1 \%$ silicon particles that are mixed in the aluminum during fabrication so the wire can be drawn to the small diameter. These particles tend to start moving as soon as the wire has completed the final annealing process. These particles as they move will "clump" together, leaving soft spots in the wire where they vacated and hard spots in the wire where they accumulate. This phenomenon does not become critical to the wire bonding process until the wire is approximately a year old.

This information prompted other evaluations to be run with wire aging. Onemil aluminum wire bonding, prior to November 1988, had been performed with wire that was nearly two years old. An experiment was run to compare 3-month old wire with 16-month old wire from the same vendor. Table 3 is a comparison of the two different age wires. Aside from the usual crater-sensitive component (SA3636) that has been used on previous evaluations, there were some additional components added to the evaluation. These LCC discrete component types had experienced electrical failures due to cratering and were considered good candidates for these evaluations. The lower crater percentages $(0.6 \%$ and $0.2 \%)$ of the newer wire are an indication that older wire may contribute to the cratering problem, since the crater percentages of 
Table 3. Wire Evaluations, First Vendor

\begin{tabular}{|c|c|c|c|c|c|c|c|}
\hline \multirow{2}{*}{$\begin{array}{l}\text { Time } \\
\text { (ms) }\end{array}$} & \multirow{2}{*}{$\begin{array}{l}\text { Force } \\
\text { (g) }\end{array}$} & \multirow{2}{*}{ Power } & \multirow{2}{*}{$\begin{array}{l}\text { Number } \\
\text { of Bonds }\end{array}$} & \multirow{2}{*}{$\begin{array}{l}\text { Wire Age } \\
\text { (Months) }\end{array}$} & \multicolumn{2}{|c|}{ Craters } & \multirow{2}{*}{ Component } \\
\hline & & & & & Number & Percent & \\
\hline 30 & 30 & 2.95 & 640 & 16 & 14 & 2.2 & SA3636 \\
\hline 30 & 30 & 2.95 & 320 & 16 & 3 & 0.9 & 373602 \\
\hline 30 & 30 & 2.95 & 960 & 4 & 6 & 0.6 & SA3636 \\
\hline 30 & 30 & 2.95 & 640 & 4 & 1 & 0.2 & 373602 \\
\hline
\end{tabular}

the older wire are somewhat higher $(2.2 \%$ and $0.9 \%$ ).

These parameters were producing fewer craters than had been experienced so the bonder parameter settings were changed to a force of $30 \mathrm{~g}$, time of $30 \mathrm{~ms}$, and power to operator variable between $x$ and $y$ to achieve proper deformation and pull strength. Also the material standard drawing for wire was changed to limit shelf life to one year.

\section{Six-Parameter Evaluation}

A study was designed using the refined parameters shown in Table 4 to further improve the crater rate.

Each device number was bonded with the indicated variable settings, and 12 bonds were made per run. Three devives were used for this evaluation: a diode and two transistors. These devices had proven to be crater sensitive in previously scrapped lots of LCCs.

The matrix design allowed two values to be assigned for each variable.

- The two wire hardnesses used were the current production wire (16 to $18-\mathrm{g}$ breaking load) and a softer t pe (14 to $16-g$ breaking load).

- The bond tools evaluated included a flat tool which was used in the production process and a concave tool used in industry for better wire control and promoted as possibly an aid in reducing cratering.

- The KCD wire bonding process used a contact velocity of 15 in conversations with personnel at Kulicke \& Soffa, slower contact velocities were recommended to reduce cratering. Therefore, contact velocities of 21 and 27 were chosen for the experiment.

- A bond force of $30 \mathrm{~g}$ is the industry standard and is the force that KCD has used. A 50-g force and a $30 \mathrm{gg}$ force were chosen for the evaluation \#3.

- The bonding time of the original process is $30 \mathrm{~ms}$. For this evaluation, times of $20 \mathrm{~ms}$ and $40 \mathrm{~ms}$ were used.

- With the time and force variables established, bond power was picked at a minimum and maximum level to complete the bonding envelope. The numbers represented in the matrix for 
Table 4. LCC Evaluation Matrix

\begin{tabular}{|c|c|c|c|c|c|c|}
\hline Device \# & $\begin{array}{l}\text { Wire } \\
\text { (g/bl) }\end{array}$ & Tool & $\begin{array}{l}\text { Contact } \\
\text { Velocity }\end{array}$ & $\begin{array}{l}\text { Force } \\
\text { (g) }\end{array}$ & Power & $\begin{array}{l}\text { Time } \\
\text { (ms) }\end{array}$ \\
\hline 1 & $14-16$ & Flat & 21 & 30 & 3.5 & 20 \\
\hline 2 & $16-18$ & Concave & 21 & 30 & 4.5 & 40 \\
\hline 3 & $16-18$ & Flat & 27 & 50 & 4.5 & 20 \\
\hline 4 & $14-16$ & Concave & 27 & 50 & 3.5 & 40 \\
\hline 5 & $16-18$ & Concave & 21 & 30 & 3.5 & 20 \\
\hline 6 & $14-16$ & Flat & 21 & 30 & 4.5 & 40 \\
\hline 7 & $16-18$ & Flat & 27 & 50 & 3.5 & 40 \\
\hline 8 & $14 \cdot 16$ & Concave & 27 & 50 & 4.5 & 20 \\
\hline 9 & $16-18$ & Flat & 27 & 30 & 3.5 & 20 \\
\hline 10 & $14-16$ & Flat & 21 & 50 & 4.5 & 20 \\
\hline 11 & $16-18$ & Concave & 21 & 50 & 3.5 & 40 \\
\hline 12 & $14-16$ & Concave & 27 & 30 & 4.5 & 40 \\
\hline 13 & $14-16$ & Concave & 27 & 30 & 3.5 & 20 \\
\hline 14 & $14-16$ & Flat & 21 & 50 & 3.5 & 40 \\
\hline 15 & $16-18$ & Flat & 27 & 30 & 4.5 & 40 \\
\hline 16 & $16-18$ & Concave & 21 & 50 & 4.5 & 20 \\
\hline 17 & $16-18$ & Flat & 21 & 30 & 4.5 & 20 \\
\hline 18 & $14-16$ & Concave & 21 & 30 & 3.5 & 40 \\
\hline 19 & $14-16$ & Flat & 27 & 50 & 3.5 & 20 \\
\hline 20 & $16-18$ & Concave & 27 & 50 & 4.5 & 40 \\
\hline 21 & $16 \cdot 18$ & Flat & 21 & 30 & 3.5 & 40 \\
\hline 22 & $14-16$ & Concave & 21 & 30 & 4.5 & 20 \\
\hline 23 & $16-18$ & Concave & 27 & 50 & 3.5 & 20 \\
\hline 24 & $14-16$ & Flat & 27 & 50 & 4.5 & 40 \\
\hline 25 & $16-18$ & Flat & 21 & 50 & 3.5 & 20 \\
\hline 26 & $14-16$ & Flat & 27 & 30 & 4.5 & 20 \\
\hline 27 & $16-18$ & Concave & 27 & 30 & 3.5 & 40 \\
\hline 28 & $14-16$ & Concave & 21 & 50 & 4.5 & 40 \\
\hline 29 & $14-16$ & Concave & 21 & 50 & 3.5 & 20 \\
\hline 30 & $14-16$ & Flat & 27 & 30 & 3.5 & 40 \\
\hline 31 & $16-18$ & Concave & 27 & 30 & 4.5 & 20 \\
\hline 32 & $16-18$ & Flat & 21 & 50 & 4.5 & 40 \\
\hline
\end{tabular}


the power are only dial settings on the generator.

Prior to performing the evaluation, the variable combinations were checked to ensure that acceptable bonds could be made from each setting.

After completion of the bonding on the matrix, all 384 bonds $(32 \times 12)$ were destructively pull tested, the metalization was etched from the bond pads, and the devices were inspected for craters. Table 5 contains the results of the evaluation.

Thirteen cracks were observed, with only one being of substantial size. The remaining twelve were very small. SEM was performed on the very small ones, which revealed that the defects did not penetrate the oxide layer into the silicon. These are not considered cracks or craters, but they are an indication of damage that may lf,ad to craters on subsequent bonds. An analysis of the data was completed to select a set of parameters which would be retested to determine if production activity could begin with the confidc nce that the crater rate would be at a $1 \%$ level or less. Devices which showed low pull strength ( $3.5 \mathrm{~g}$ or less) and any cratering were eliminated.

The softer wire was included in this evaluation to determine if the wire made an appreciable difference in the crater rate and to gather information for further evaluations on the wire. There was less damage using the softer wire. Changing to the 14 to $16-g$ wire would require further long-term reliability studies on the bonds using this wire. Further evaluation of sofi wire will be completed.

The concave tool was not used because one of the largest craters occurred with a concave tool. Further tool evaluations need to be performed to verify this.

There was not a significant difference in the data that was generated using the $50-\mathrm{g}$ force compared to the $30 \mathrm{-g}$ force. It is iritei esting to note that this substantial increase in force did not produce more cratering as expected. Further evaluations using a higher force will be performed along with parameters which use the 14 to $16-\mathrm{g} / \mathrm{bl}$ wire, the concave tool, and a $50-\mathrm{g}$ force.

Using the above criteria, the parameters were reduced to the set which is displayed in Table 4 as device \#17. The significant difference between these parameters and those which had been used in production is a slower contact velocity and a bond time of $20 \mathrm{~ms}$ rather than $30 \mathrm{~ms}$.

A verification test was performed with 40 bonds made with this set of parameters and visually inspected. The bonds were acceptable, but deform - '.ion was excessive. Lower power produced bonds which looked better and had very good pull strengths. To further improve this set of parameters, it was decided to use a slower contact velocity of 27 . This new set of parameters can be seen along with the old parameters in Table 6.

Prior to beginning wire bonding on production devices this set of parameters was tested on the same crater-sensitive devices that were used on the matrix evaluation. The results of this bonding evaluation can be seen in Table 7 . This data was reviewed and found to be acceptable for production devices.

\section{Accomplishments}

Cratering has not been completely eliminated from the ultrasonic aluminum 
Table 5. LCC Evaluation Matrix Results

\begin{tabular}{|c|c|c|c|c|c|c|}
\hline Device \# & $\begin{array}{l}\text { Standard } \\
\text { Deviation }\end{array}$ & $\begin{array}{l}\text { Average } \\
\text { (g) }\end{array}$ & $\begin{array}{l}\text { Minimum } \\
\text { (g) }\end{array}$ & $\begin{array}{l}\text { Maximum } \\
\text { (g) }\end{array}$ & Delams & Craters \\
\hline 1 & 0.614 & 8.1 & 7.2 & 9.6 & 0 & 0 \\
\hline 2 & 2.141 & 5.7 & 0.0 & 6.4 & 0 & 0 \\
\hline 3 & 1.001 & 7.5 & 5.8 & 9.2 & 0 & 0 \\
\hline 4 & 0.881 & 6.6 & 4.7 & 7.5 & 0 & 0 \\
\hline 5 & 1.384 & 9 & 6.1 & 12.0 & 2 & 0 \\
\hline 6 & 2.016 & 3.6 & 0.0 & 7.0 & 0 & 0 \\
\hline 7 & 1.411 & 7.6 & 5.0 & 10.3 & 0 & 0 \\
\hline 8 & 0.791 & 5.5 & 4.1 & 6.4 & 0 & 0 \\
\hline 9 & 2.373 & 6.8 & 1.6 & 9.6 & 5 & 3 \\
\hline 10 & 2.02 & 3.4 & 0.0 & 5.8 & 0 & 0 \\
\hline 11 & 1.275 & 6.8 & 4.6 & 8.5 & 0 & 0 \\
\hline 12 & 1.821 & 5.3 & 1.4 & 8.7 & 0 & 0 \\
\hline 13 & 1.395 & 8.3 & 6.6 & 11.3 & 3 & 0 \\
\hline 14 & 1.01 & 6.3 & 4.1 & 7.1 & 0 & 0 \\
\hline 15 & 3.229 & 4.7 & 0.0 & 9.5 & 0 & 0 \\
\hline 16 & 1.316 & 6.4 & 4.3 & 8.3 & 0 & 0 \\
\hline 17 & 1.098 & 6.9 & 5.0 & 8.2 & 0 & 0 \\
\hline 18 & 1.025 & 7.2 & 5.9 & 9.0 & 0 & 1 \\
\hline 19 & 1.01 & 7 & 5.8 & 8.8 & 2 & 0 \\
\hline 20 & 1.143 & 5.5 & 2.8 & 7.1 & 0 & 0 \\
\hline 21 & 1.302 & 8.1 & 5.9 & 10.2 & 1 & 3 \\
\hline 22 & 2.22 & 5.2 & 0.0 & 6.6 & 0 & 0 \\
\hline 23 & 0.948 & 7.3 & 5.3 & 8.2 & 4 & 1 \\
\hline 24 & 1.161 & 4.2 & 2.2 & 6.0 & 0 & 0 \\
\hline 25 & 1.354 & 6.2 & 4.2 & 7.9 & 6 & 0 \\
\hline 26 & 2.028 & 4.9 & 0.0 & 7.2 & 0 & 0 \\
\hline 27 & 1.043 & 9 & 7.4 & 10.1 & 3 & 3 (1 large) \\
\hline 28 & 0.724 & 5.2 & 4.2 & 6.5 & 1 & 0 \\
\hline 29 & 0.854 & 7.7 & 6.7 & 9.3 & 2 & 1 \\
\hline 30 & 1.169 & 8.3 & 6.2 & 10.3 & $" 1$ & 1 \\
\hline 31 & 2.88 & 7.6 & 2.5 & 11.8 & 2 & 0 \\
\hline 32 & 0.971 & 5.6 & 3.7 & 7.1 & 0 & 0 \\
\hline
\end{tabular}

"Greater than $5.0 \mathrm{~g}$ 
Table 6. Old and New Bonding Parameters

\begin{tabular}{|ccccccc|}
\hline Parameters & $\begin{array}{c}\text { Wire } \\
(\mathrm{g} / \mathrm{b})\end{array}$ & Tool & $\begin{array}{c}\text { Contact } \\
\text { Velocity }\end{array}$ & $\begin{array}{c}\text { Force } \\
(\mathrm{g})\end{array}$ & Power & $\begin{array}{c}\text { Time } \\
(\mathrm{ms})\end{array}$ \\
\hline Old & $16-18$ & Flat & 15 & 30 & 3.50 & 30 \\
New & $16-18$ & Flat & 27 & 30 & 4.00 & 20 \\
\hline
\end{tabular}

Table 7. Number of Craters From New Parameters

\begin{tabular}{|ccc|}
\hline Part & Bonds/Craters & Crater \% \\
\hline Diode & $104 / 0$ & 0 \\
Transistor 1 & $80 / 1$ & 1.2 \\
Transistor 2 & $240 / 5$ & 2.0 \\
\hline Overall & $424 / 6$ & 1.4 \\
\hline
\end{tabular}

wire bonding process, but from these evaluations, reduced incidence of cratering has occurred in wire bonding. The interaction of time, power, and force has been demonstrated to influence the crater rate. The aluminum wire has also been shown to have a negative impact on bond quality if it is more than a year old and not stored in dry nitrogen.

\section{Future Work}

Bonding characterization will be completed on this process using the Mario-Perez Wilson five-stage methodology for optimizing manufacturing processes. As part of this characterization it is planned to implement a reliable and fast method to measure the ultrasonic energy output at the bond tool. When this work is completed, a method will be established that can be applied to ultrasonic bonders to consistently duplicate bonding parameters.

Bonding variables to be evaluated that may have the potential to impact cratering are indicated below.

- External vibrations caused by clean room blower motors. These vibrations could be transferred to the bonder head, down through the tool, and onto work surface of the die.

- Inconsistent variations in the ultrasonic energy. High peaks in the energy may be causing the cratering. A reliable method to measure the ultrasonic energy at the bond tool is being investigated.

- An upgraded model of the existing bonders may reduce cratering. Evaluation devices will be sent to 
Kulicke \& Soffa for bonding on the K\&S 1472 bonder.

- The bond wire hardness that is presently being used may be causing cratering. An evaluation of softer wire is being performed.

- Variations in the aluminum metalization thickness of die. The metalization thicknesses of all die used in LCC packaging will be measured to determine if there is a correlation between thickness and cratering. 

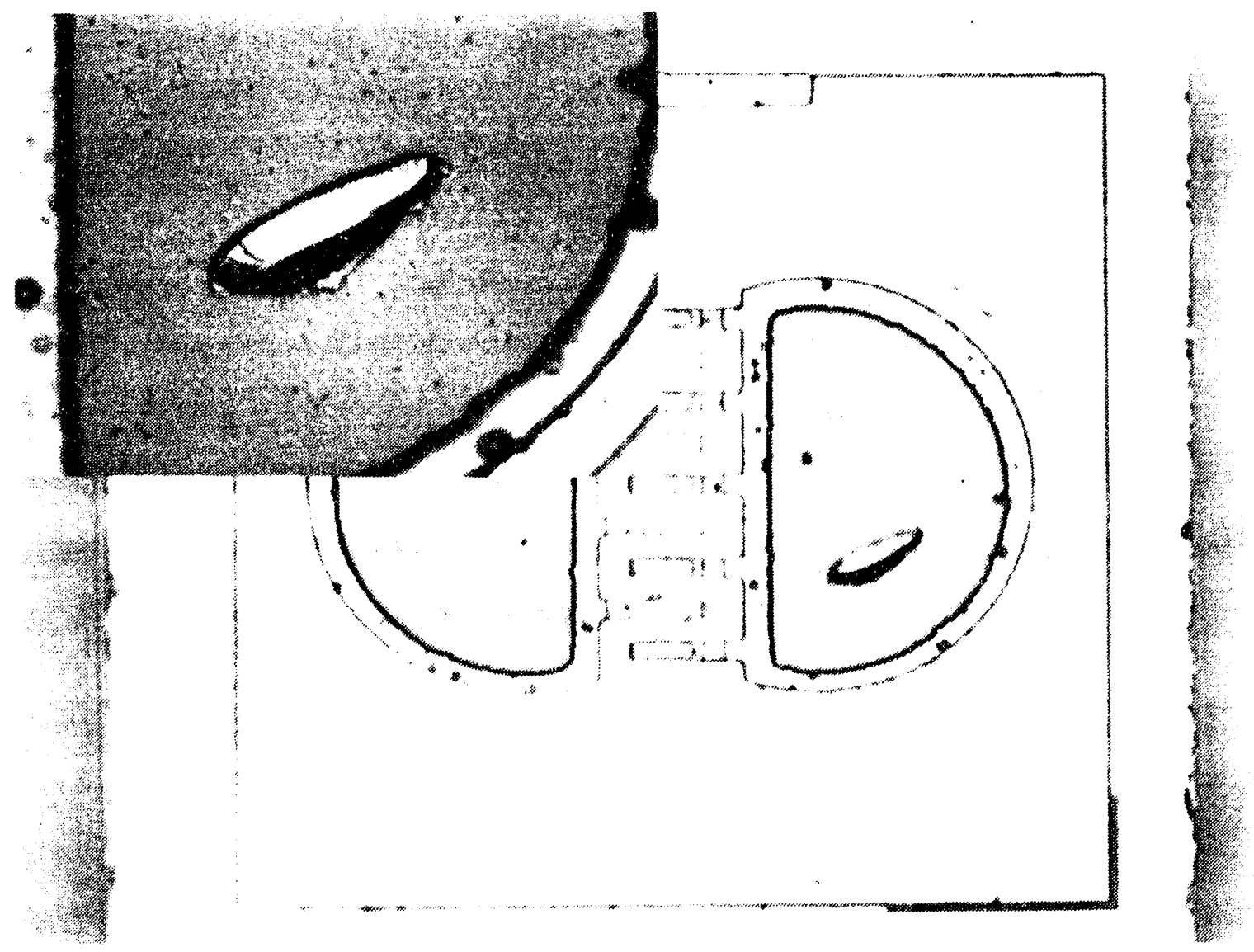

Figure 1. A Transistor With $3 \times 5$-Mil Bond Pads. (Approximately 200X. The device has been etched back to reveal a crater 1.5 mils in the longest direction.) 




Figure 2. A Diode With 4-Mil-Diameter Bond Pad. (Approximately 200X. The device has been etched back to reveal a crater 1.0 mil in diameter. This crater represents "worst case," both in size and depth.) 

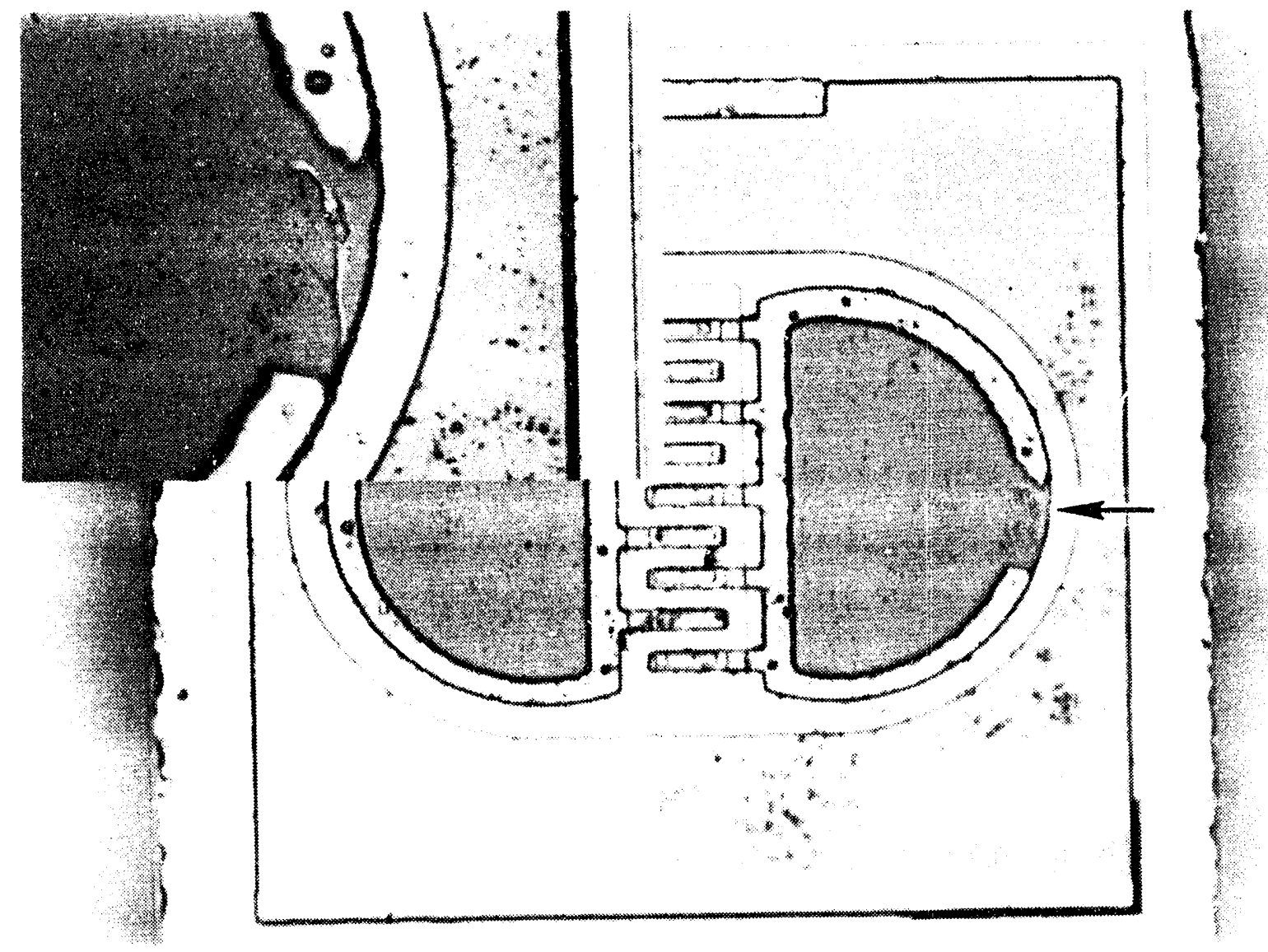

Figure 3. Transistor With a 1-Mil Crack on the Perimeter of the Bond Pad. (Approximately $200 \mathrm{X}$. The detail of the inset shows that there is almost sufficient cracking to cause a divot in the silicon. Detection of this type of crater is difficult because most of the silicon material is still remaining.) 


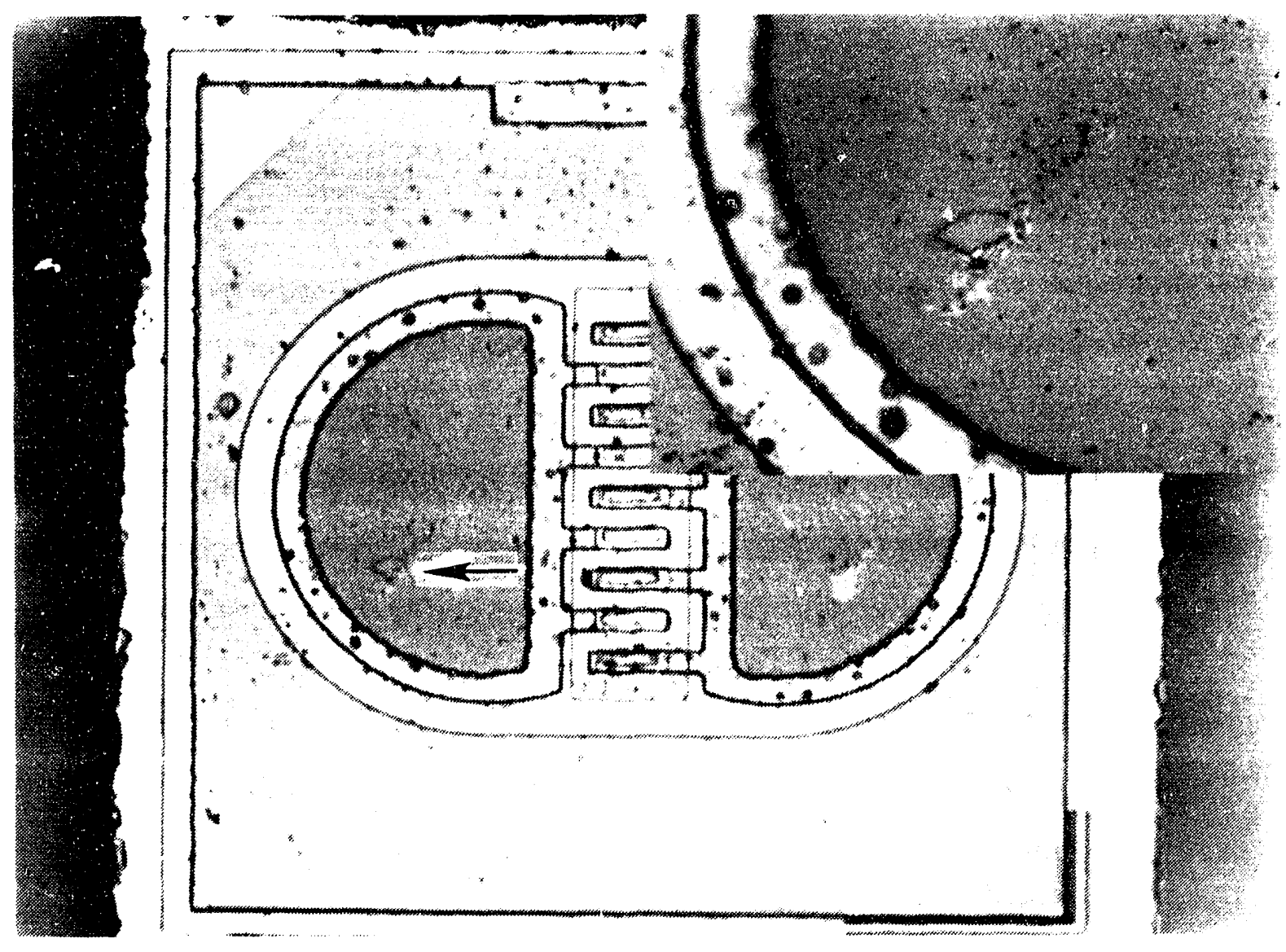

Figure 4. Crater Which is $0.5 \mathrm{Mil}$ in the Longest Direction. (Approximately 200X. The silicon is fractured around three sides to form a triangular shape.) 


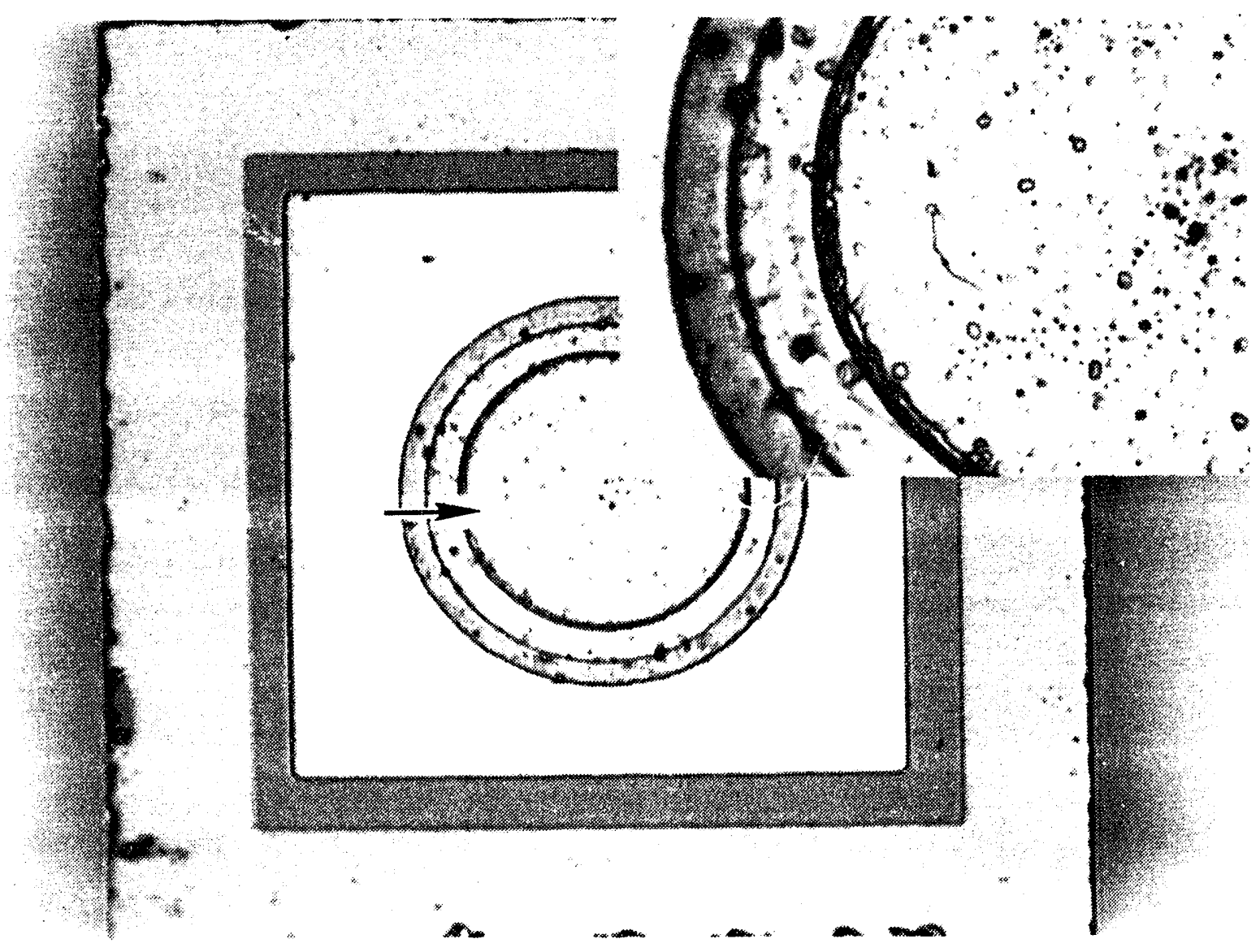

Figure 5. Considerable Damage to the Silicon in a Crater That Is Difficult to Detect (Approximately 200X) 


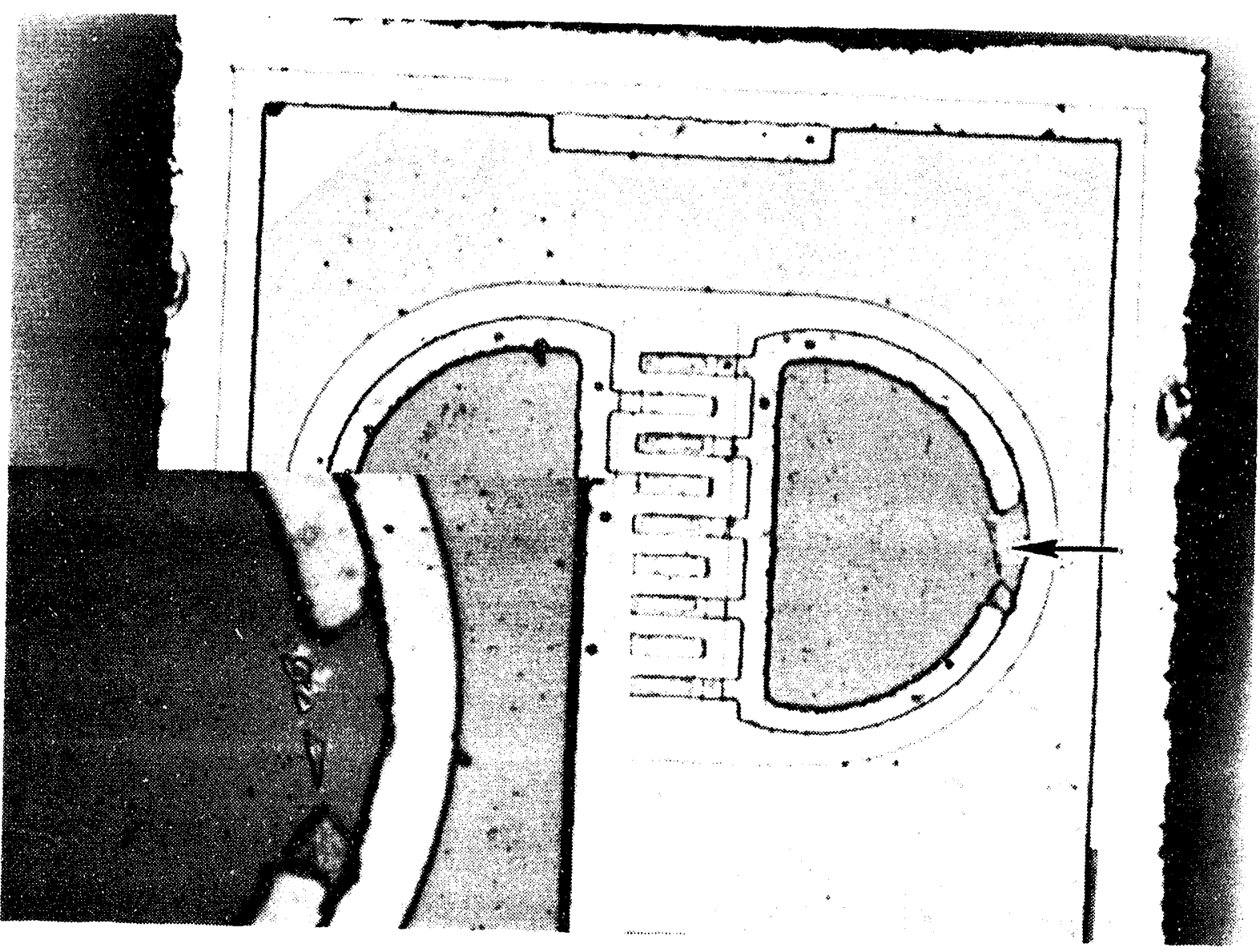

Figure 6. Two Different Areas of Damage. (Approximately 200X. The lower area has fractured the silicon, but an SEM of the upper area will probably reveal that the damage has
not penetrated the silicon oxide.) 


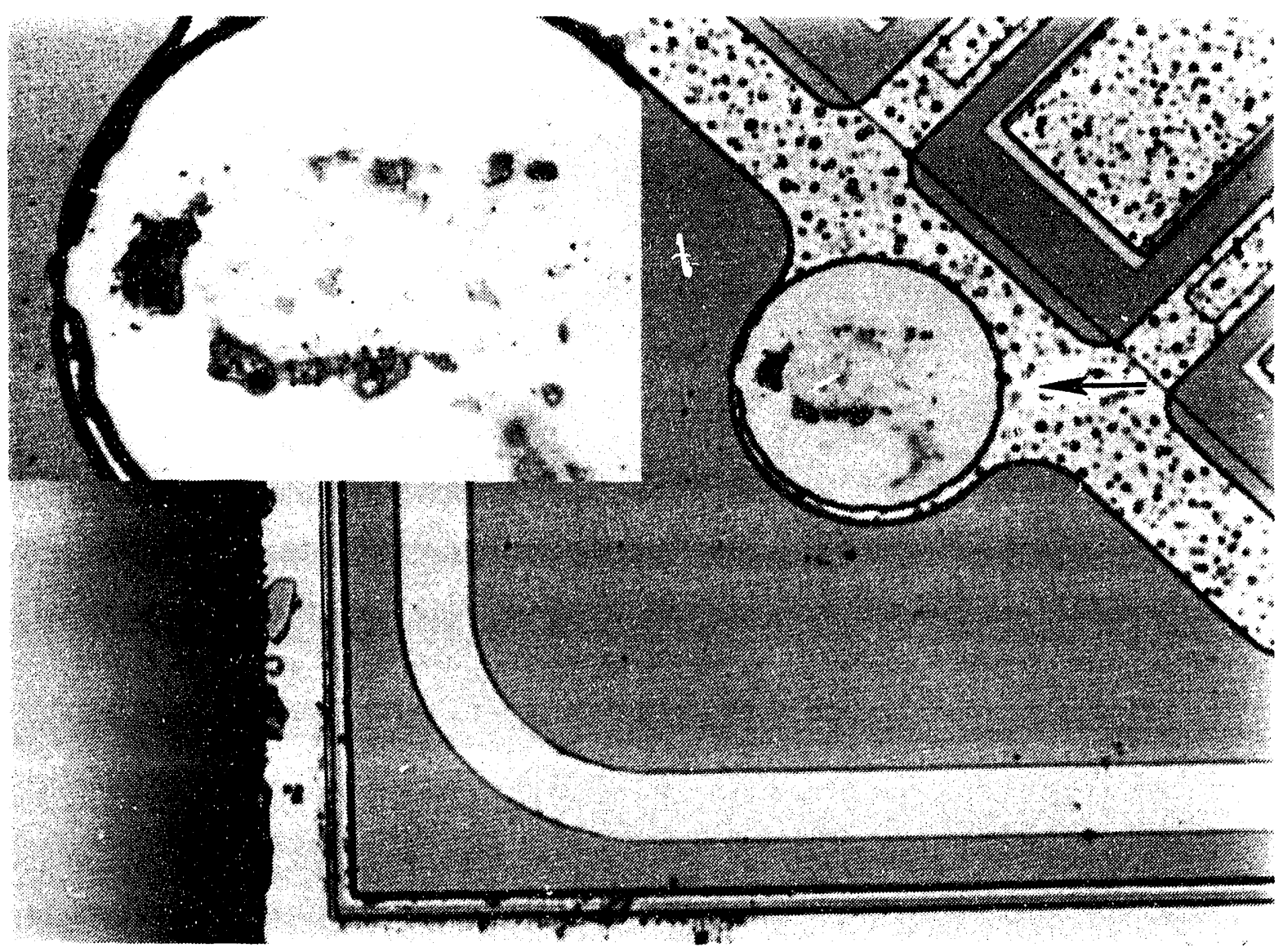

Figure 7. Outline of the Bond After the Metalization Has Been Etched Away. (Approximately 200X. There is also surface mechanical damage, which an SEM will clearly show does not penetrate the silicon oxide.) 


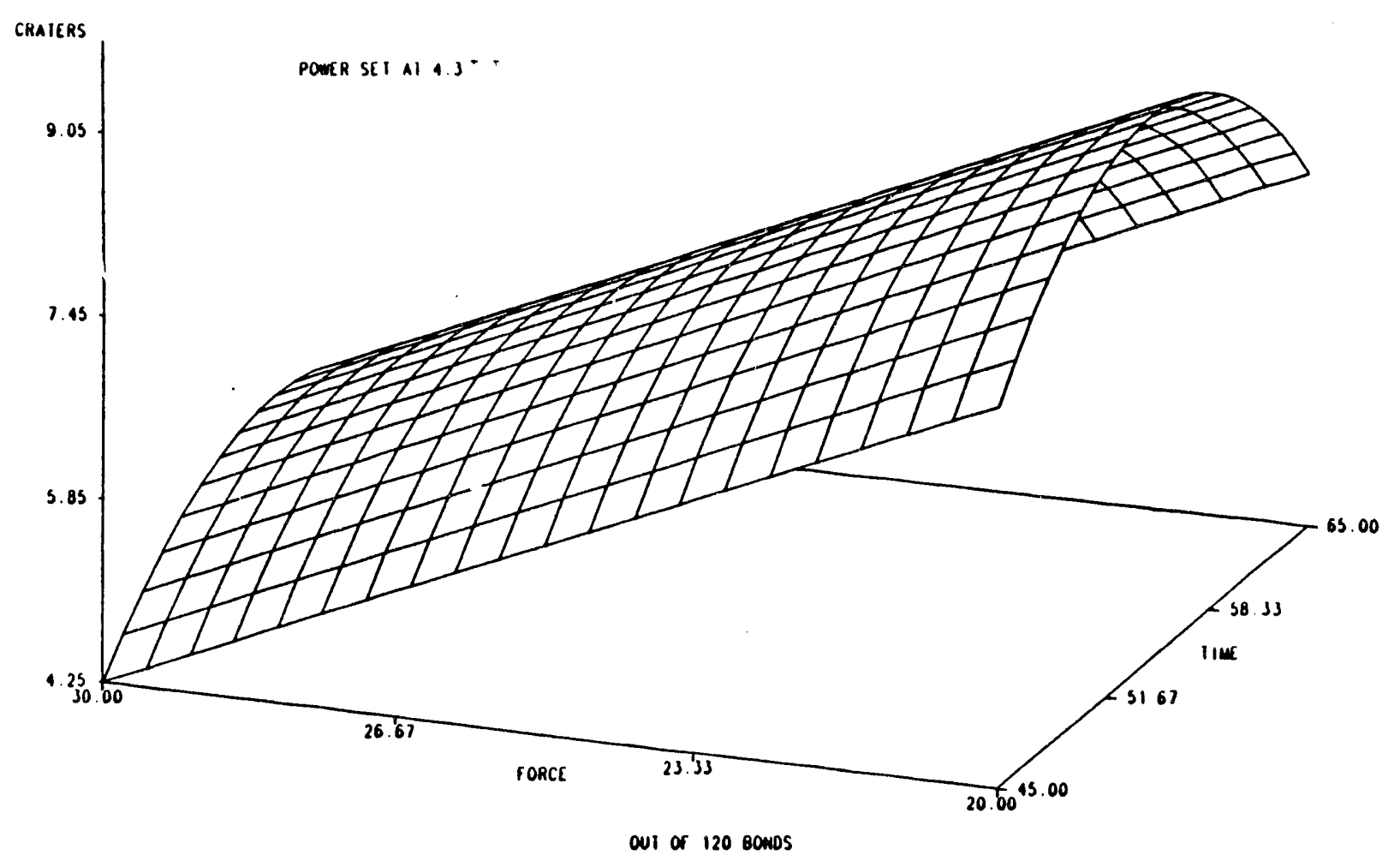

Figure 8. Bonding Experiment, Number of Small Craters

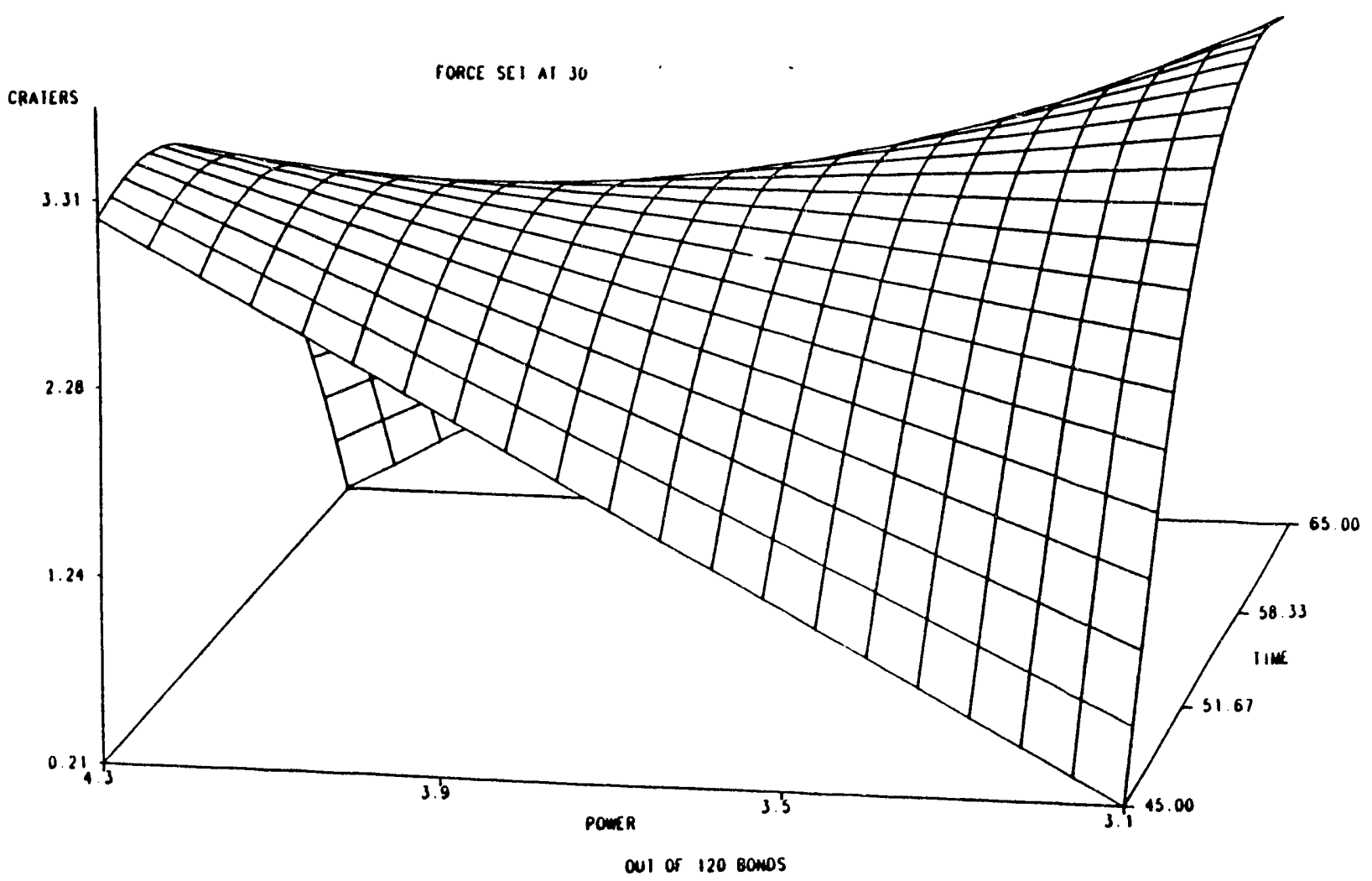

Figure 9. Bonding Experiment, Number of Large Craters 


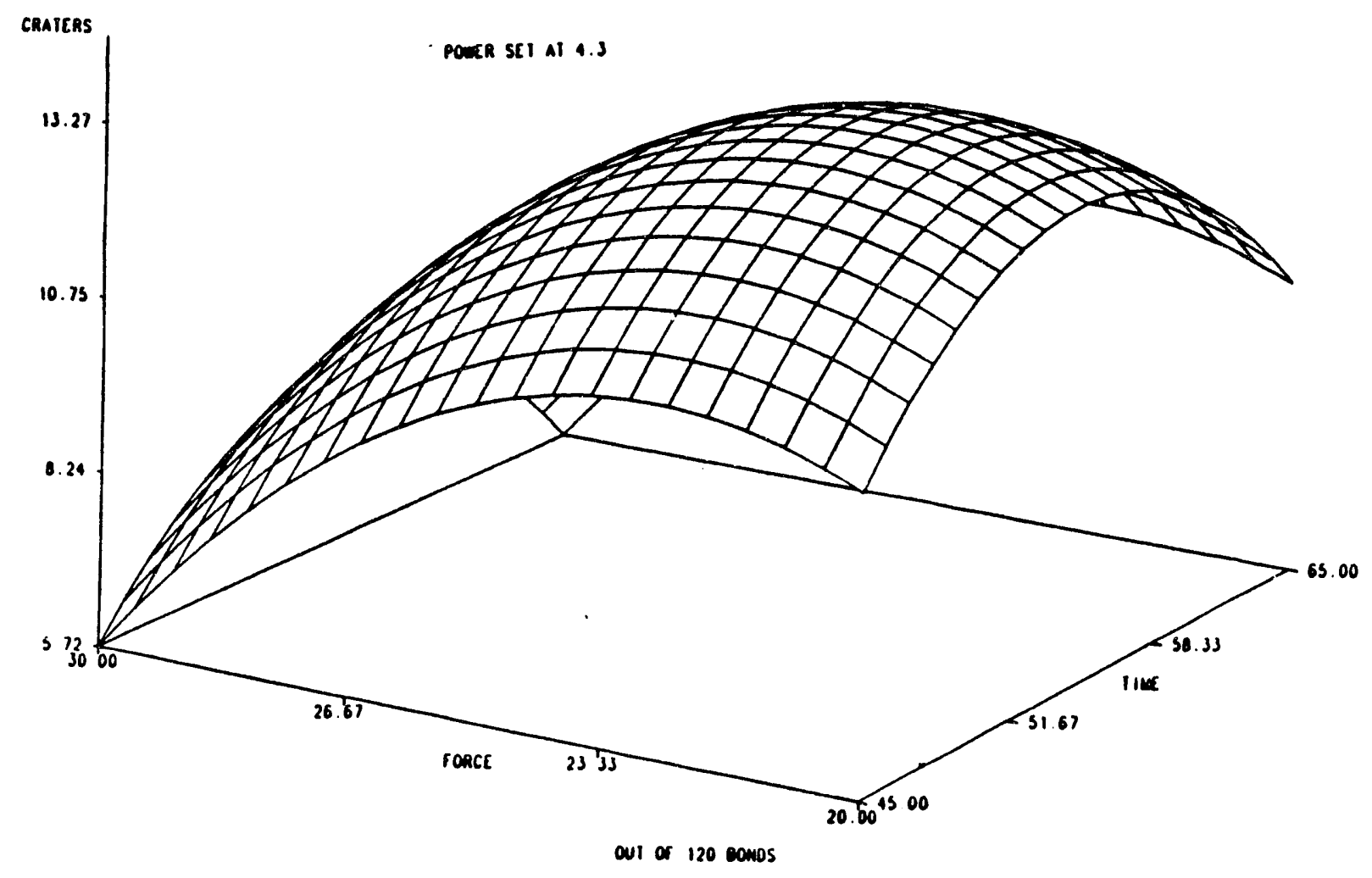

Figure 10. Bonding Experiment, Number of Total Craters 

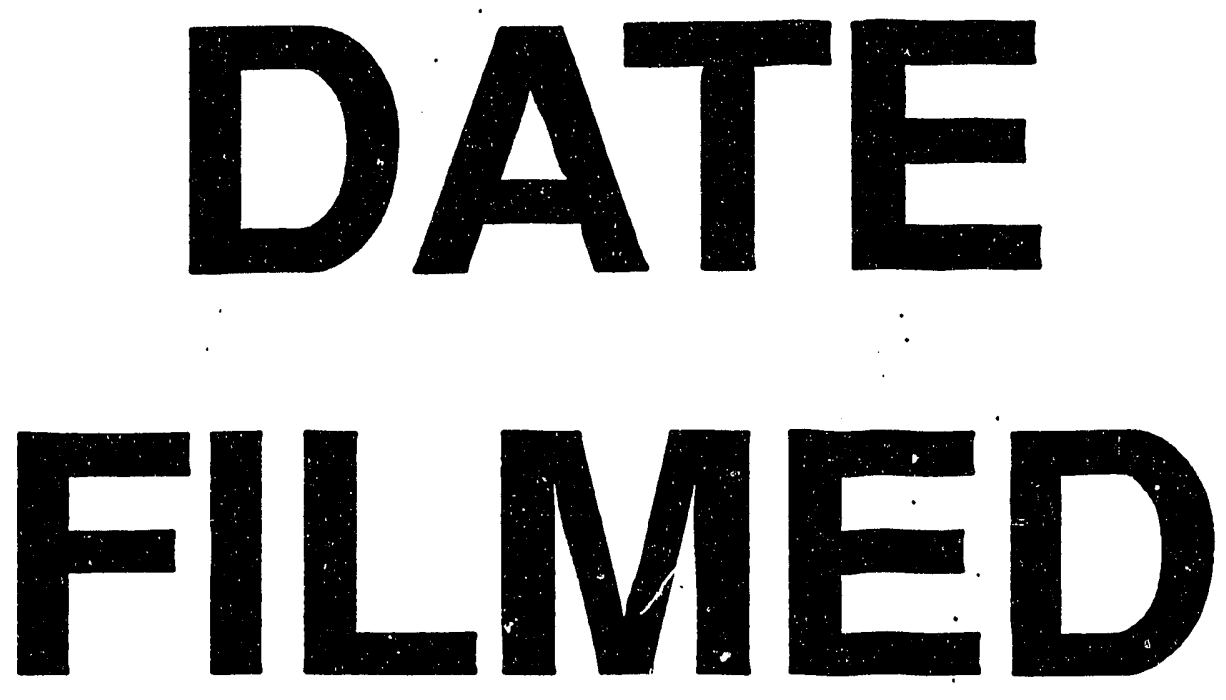

$10 / 20 / 93$
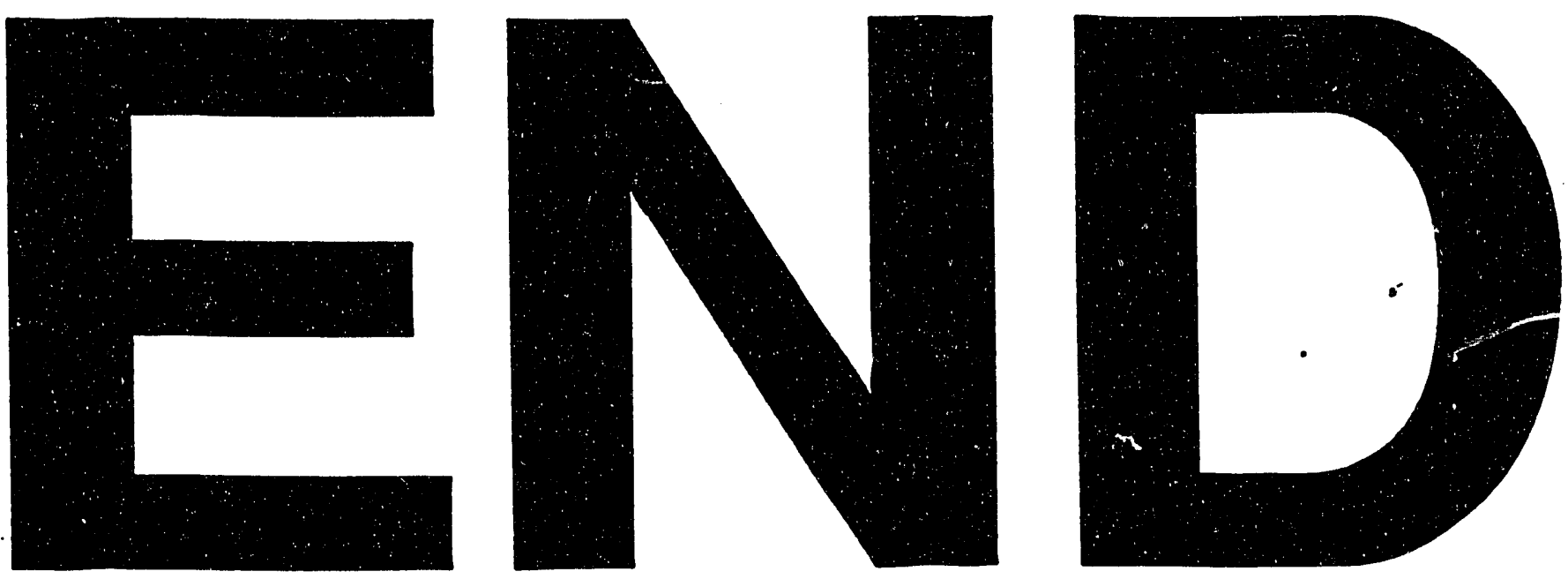